\section{RMD Open}

Rheumatic \&

Musculoskeletal Diseases

\title{
Cardiac involvement in adult and juvenile idiopathic inflammatory myopathies
}

Thomas Schwartz, ${ }^{1,2}$ Louise Pyndt Diederichsen, ${ }^{3}$ Ingrid E Lundberg, ${ }^{4}$ Ivar Sjaastad, ${ }^{2,5}$ Helga Sanner $^{1,6}$

To cite: Schwartz T, Diederichsen LP, Lundberg IE, et al. Cardiac involvement in adult and juvenile idiopathic inflammatory myopathies. RMD Open 2016;2:e000291. doi:10.1136/rmdopen-2016000291

- Prepublication history and additional material for this paper is available online. To view these files please visit the journal online (http://dx.doi.org/10.1136/ rmdopen-2016-000291).

Received 25 June 2016 Revised 30 August 2016 Accepted 7 September 2016

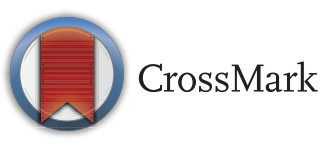

For numbered affiliations see end of article.

Correspondence to Professor Ivar Sjaastad; ivar. sjaastad@medisin.uio.no

\section{ABSTRACT}

Idiopathic inflammatory myopathies (IIM) include the main subgroups polymyositis (PM), dermatomyositis (DM), inclusion body myositis (IBM) and juvenile DM (JDM). The mentioned subgroups are characterised by inflammation of skeletal muscles leading to muscle weakness and other organs can also be affected as well. Even though clinically significant heart involvement is uncommon, heart disease is one of the major causes of death in IIM. Recent studies show an increased prevalence of traditional cardiovascular risk factors in JDM and DM/PM, which need attention. The risk of developing atherosclerotic coronary artery disease is increased twofold to fourfold in DM/PM. New and improved diagnostic methods have in recent studies in PM/DM and JDM demonstrated a high prevalence of subclinical cardiac involvement, especially diastolic dysfunction. Interactions between proinflammatory cytokines and traditional risk factors might contribute to the pathogenesis of cardiac dysfunction. Heart involvement could also be related to myocarditis and/or myocardial fibrosis, leading to arrhythmias and congestive heart failure, demonstrated both in adult and juvenile IIM. Also, reduced heart rate variability (a known risk factor for cardiac morbidity and mortality) has been shown in long-standing JDM. Until more information is available, patients with IIM should follow the same recommendations for cardiovascular risk stratification and prevention as for the corresponding general population, but be aware that statins might worsen muscle symptoms mimicking myositis relapse. On the basis of recent studies, we recommend a low threshold for cardiac workup and follow-up in patients with IIM.

\section{INTRODUCTION}

Idiopathic inflammatory myopathies (IIMs) are a heterogeneous group of diseases characterised by proximal muscle weakness and inflammatory changes in skeletal muscle. Adults or children can be affected, and in adult onset IIM, cardiovascular complications represent a major cause of death. However,

\section{Key messages}

Idiopathic inflammatory myopathies (IIMs) are associated with increased risk of cardiac involvement mainly due to atherosclerosis and myocarditis.

- A low threshold for cardiac workup and follow-up in IIM is recommended.

- Monitor carefully when using statins in IIM: statins may worsen muscle symptoms mimicking myositis relapse.

there is limited information on heart involvement in IIM, both due to the rarity of the diseases and because manifest cardiac complications in these patients are uncommon. In other rheumatic diseases, like rheumatoid arthritis (RA) and systemic lupus erythematosus (SLE), cardiac involvement is well documented. ${ }^{1-3}$ More recently, registry-based studies reported associations between atherosclerosis and rare rheumatic and autoimmune diseases, including IIM. ${ }^{4}$ Whether atherosclerosis is the driving force of the cardiac involvement in IIM or mechanisms such as myocardial inflammation, systemic inflammation or small vessel vasculitis play equally important roles remains unknown.

Historically, cardiac involvement in IIM has been demonstrated by ECG ${ }^{6-8}$ continuous electrocardiographic monitoring ${ }^{9-11}$ and autopsies. $^{12} 13$ Today, new cardiac imaging modalities such as Tissue Doppler imaging (TDI) by echocardiography, ${ }^{14-18}$ Cardiac MR (CMR), ${ }^{19}{ }^{99 m}$ technetium pyrophosphate $\left({ }^{99 m}\right.$ Tc-PYP) scintigraphy ${ }^{18} 2021$ and coronary artery calcification on CT $\operatorname{scan}^{22}$ can detect subtle cardiac abnormalities. Owing to their high sensitivity, these methods often suggest a higher frequency of heart disease in IIM than what is clinically evident. However, despite this discrepancy, subclinical cardiac pathology might represent early stages in 
cardiac remodelling that will later manifest as clinical heart disease, and can therefore not be ignored. Further research is needed to clarify if subclinical disease will eventually develop into clinically manifest cardiac disease. $^{23}$

Beyond general guidelines for cardiac diseases, specific recommendations for treatment or cardiac follow-up of patients with IIM are non-existing. This review summarises current evidence of cardiac complications in patients with the IIM subgroups polymyositis (PM), dermatomyositis (DM), inclusion body myositis (IBM) and juvenile IIM, where juvenile dermatomyositis (JDM) is by far the most common subgroup. We will also discuss possible disease mechanisms and what make these patients particularly vulnerable, beyond the traditional cardiovascular $(\mathrm{CV})$ risk factors.

\section{CARDIAC MORTALITY}

The three major causes of cardiac mortality in patients with $\mathrm{IIM}^{24}$ are similar to those of the population in general: congestive heart failure, myocardial infarction and arrhythmias. The reported mortality due to cardiac involvement in adult onset IIM varies substantially in the literature. ${ }^{25-30}$ Eleven by $20(55 \%)$ of the deaths were due to cardiac aetiology in a Hungarian longitudinal study, ${ }^{26} 36 \%$ of 149 deaths were due to circulatory causes (not further specified) in a register-based Finnish study, whereas $12 / 87(14 \%)$ deaths were due to cardiac causes in a recent population-based Norwegian study. ${ }^{31}$ Also, in retrospective follow-up studies on patients with PM and DM, cardiac disease was one of the four most frequent causes of death. ${ }^{32} 33$ The discrepancies between the studies regarding aetiology of deaths may be due to variable study designs and populations, variable definitions of cardiac involvement, limited numbers of patients in some of the series and studies performed at different time periods and decades.

Not surprisingly, cardiac disease has been associated with poor prognosis: in one study, 9 of 28 patients (32\%) with PM or DM and cardiac involvement died within 8 years, whereas only 4 of the remaining 48 patients $(8 \%)$ died during the same period. ${ }^{34}$ In juvenile IIM, a Canadian study reported cardiac involvement in 3/17 reported deaths, but these patients also had involvement of other organ systems. ${ }^{35}$

\section{TRADITIONAL CARDIOVASCULAR RISK FACTORS}

Increasing evidence suggests that traditional CV risk factors (including diabetes, hypertension, dyslipidaemia, obesity and smoking) are more prevalent in adult onset IIM than in the general population (table 1); this has especially been found for abdominal obesity. ${ }^{22} 3637$ Increased prevalence of hypertension and dyslipidaemia has also been shown in untreated patients with IIM, ${ }^{38} 39$ which indicates an effect of the disease per se in addition to a possible effect of long-term glucocorticoid treatment. Also in JDM, hypertension and dyslipidaemia have been demonstrated (table 1). ${ }^{40-42}$ These findings are in line with $\mathrm{RA}^{43}$ and SLE. ${ }^{44}$

The potential influence of and associations between traditional CV risk factors, disease-specific parameters and cardiac disease in IIM have so far only been addressed in one study. ${ }^{22}$ In this study, traditional CV risk factors and severe coronary artery calcification (CAC) were commonly found in patients with PM/DM. However, severe CAC was not associated with $\mathrm{PM} / \mathrm{DM}$ per se, but rather with age and smoking in these patients. Thus, clinicians should pay attention to the presence of traditional CV risk factors.

\section{CLINICAL HEART INVOLVEMENT \\ Cardiac dysfunction and heart failure}

Heart failure is a clinical syndrome with characteristic symptoms and physical findings, while 'cardiac dysfunction' is a condition of cardiac pathology demonstrated by various cardiac imaging techniques, but without clinical symptoms. Systolic heart failure/dysfunction is due to impaired left ventricular contraction and results in reduced left ventricular ejection fraction $(\mathrm{EF})$. In diastolic heart failure/dysfunction, left ventricular $\mathrm{EF}$ is normal, but pathological stiffness of the left ventricle causes a restricted filling pattern. The symptoms of systolic and diastolic heart failure are indistinguishable. Cardiac function is quickly and well assessed by echocardiography. The common definition of systolic dysfunction is left ventricular $\mathrm{EF}<40 \%$. Diastolic dysfunction, on the other hand, is defined as E/é $>14$ (E, early diastolic transmitral flow; é early diastolic tissue velocity) and normal EF $(>50) .{ }^{45}$

Presence of severe systolic heart failure in adult onset IIM is well documented in case reports. ${ }^{46-56}$ However, controlled studies have not demonstrated increased prevalence of systolic or diastolic heart failure in IIM (table 2). On the other hand, controlled studies have shown diastolic dysfunction in adult onset IIM with impaired E/e', but no evidence of systolic dysfunction (table 2). ${ }^{1415} 1857$

In JDM, diastolic dysfunction was found in $22 \%$ of patients after a median of 17 years from disease onset (table 2) ${ }^{16}$ in addition to impaired systolic function (low long axis strain assessed by echocardiography) compared to age-matched and sex-matched controls (table 2). ${ }^{17}$

Whether systolic and diastolic heart failure represent the two extremes on a continuum of cardiac damage $e^{58}$ or whether they are two separate entities, is still a matter of debate. ${ }^{59}$ Interestingly, many of the referred IIM studies showed an independent association between diastolic dysfunction and disease duration, ${ }^{14-16} 1857$ suggesting at least diastolic cardiac involvement to be a long-term complication of IIM, and only follow-up studies can show if these patients develop heart failure. Thus, the findings of diastolic dysfunction in IIM need attention, since cardiac dysfunction may be seen as an asymptomatic state on the road to clinically overt heart 
Table 1 Demographic and traditional cardiovascular risk factors of patients with IIM

\begin{tabular}{|c|c|c|c|c|c|c|c|c|c|c|c|c|c|c|c|}
\hline Author, year & Group & $\mathbf{n}$ & F/M n & Age (years) & HT \% & Smoke \% & DB \% & Obese, \% & DL \% & BMI $\mathrm{kg} / \mathrm{m}^{2}$ & PG† & $\mathrm{TC}+$ & LDLc† & HDLc† & TG† \\
\hline Coyle, $2009^{40}$ & JDM & 17 & $14 / 3$ & $4.6-16.4$ & NA & 0 & 0 & 23.5 & 47.1 & $19.7 \sim$ & $\begin{array}{l}85 \sim \\
\mathrm{mg} / \mathrm{dL}\end{array}$ & $\begin{array}{l}165 \sim \\
\mathrm{mg} / \mathrm{dL}\end{array}$ & $\begin{array}{l}106 \sim \\
\mathrm{mg} / \mathrm{dL}\end{array}$ & $\begin{array}{l}39 \sim \\
\mathrm{mg} / \mathrm{dL}\end{array}$ & $\begin{array}{l}115 \sim \\
\mathrm{mg} / \mathrm{dL}\end{array}$ \\
\hline \multirow[t]{2}{*}{ de Moraes, $2013^{36}$} & DM & 84 & $67 / 17$ & 41.5 & $47.6^{*}$ & 10.7 & $17.9^{\star}$ & NA & $67.9^{\star}$ & $27.5^{\star}$ & $84^{*} \sim$ & $180 \sim$ & $88 \sim$ & $49^{*} \sim$ & $119^{*} \sim$ \\
\hline & & 105 & $83 / 22$ & 42.0 & 18.1 & 11.4 & 1.0 & & 49.5 & 25.4 & $\begin{array}{l}80 \sim \\
\mathrm{mg} / \mathrm{dL}\end{array}$ & $\begin{array}{l}187 \sim \\
\mathrm{mg} / \mathrm{dL}\end{array}$ & $\begin{array}{l}113 \sim \\
\mathrm{mg} / \mathrm{dL}\end{array}$ & $\begin{array}{l}54 \sim \\
\mathrm{mg} / \mathrm{dL}\end{array}$ & $\begin{array}{l}86 \sim \\
\mathrm{mg} / \mathrm{dL}\end{array}$ \\
\hline \multirow[t]{2}{*}{ de Souza, $2014^{37}$} & PM & 35 & $27 / 8$ & 49.7 & $45.7^{\star}$ & 14.3 & $34.3^{\star}$ & NA & $71.4^{\star}$ & 27.5 & $91^{*} \sim$ & $196 \sim$ & $111 \sim$ & 57 & $149^{*} \sim$ \\
\hline & Controls & 70 & $54 / 16$ & 48.7 & 27.1 & 17.1 & 4.3 & & 51.4 & 26.0 & $\begin{array}{l}81 \sim \\
\mathrm{mg} / \mathrm{dL}\end{array}$ & $\begin{array}{l}194 \sim \\
\mathrm{mg} / \mathrm{dL}\end{array}$ & $\begin{array}{l}122 \sim \\
\mathrm{mg} / \mathrm{dL}\end{array}$ & $\begin{array}{l}55 \\
\mathrm{mg} / \mathrm{dL}\end{array}$ & $\begin{array}{l}99 \\
\mathrm{mg} / \mathrm{dL}\end{array}$ \\
\hline \multirow[t]{2}{*}{ Diederichsen $2014^{22}$} & PM/DM & 76 & $49 / 27$ & 60.0 & $71^{*}$ & 25 & $13^{*}$ & $33^{*}$ & $88 \prod^{\star}$ & 27.6 & 6.5 & 5.6 & 3.3 & 1.6 & $1.5^{\star}$ \\
\hline & Controls & 48 & $32 / 16$ & 59.4 & 42 & 17 & 0 & 10 & 73 & 26.0 & 6.0 & 5.4 & 3.1 & 1.7 & 1.1 \\
\hline \multirow[t]{2}{*}{ Eimer, $2011^{41}$} & JDM & 8 & $3 / 5$ & 38 & NA & 25 & NA & NA & NA & $23 \sim$ & $94 \sim$ & NA & $102^{*} \sim$ & $40^{\star} \sim$ & $75 \sim$ \\
\hline & Controls & 15 & $6 / 9$ & 37 & & 0 & & & & $24 \sim$ & $\begin{array}{l}92 \sim \\
\mathrm{mg} / \mathrm{dL}\end{array}$ & & $\begin{array}{l}113 \sim \\
\mathrm{mg} / \mathrm{dL}\end{array}$ & $\begin{array}{l}53 \sim \\
\mathrm{mg} / \mathrm{dL}\end{array}$ & $\begin{array}{l}66 \sim \\
\mathrm{mg} / \mathrm{dL}\end{array}$ \\
\hline \multirow[t]{2}{*}{ Schwartz, $2014^{42}$} & JDM & 59 & $36 / 23$ & 21.5 & $12^{*}$ & 23 & 0 & NA & NA & 22.3 & NA & $4.2^{\star}$ & $2.3^{\star}$ & $1.2^{*}$ & NA \\
\hline & Controls & 59 & $36 / 23$ & 21.6 & 0 & 17 & 0 & & & 22.5 & & 4.6 & 2.7 & 1.5 & \\
\hline \multirow[t]{2}{*}{ Wang, $2013^{38}$} & DM & 41 & $30 / 11$ & 44.6 & 0 & NA & 0 & NA & 70.70 & NA & NA & 4.1 & 2.5 & $1.1^{*}$ & $2.2^{*}$ \\
\hline & Controls & 41 & $30 / 11$ & 42.4 & 0 & & 0 & & NA & & & 3.9 & 2.3 & 1.3 & 1.1 \\
\hline \multirow[t]{2}{*}{ Wang, $2013^{57}$} & PM§ & 71 & $56 / 15$ & 46.9 & 0 & NA & 0 & NA & NA & NA & 5.0 & 4.8 & $2.2^{*}$ & $2.0^{*}$ & $1.7^{*}$ \\
\hline & Controls & 71 & $56 / 15$ & 46.2 & 0 & & 0 & & & & 5.1 & 4.7 & 1.8 & 2.4 & 1.3 \\
\hline \multirow[t]{2}{*}{ Wang, $2014^{39}$} & PM‡ & 60 & $44 / 16$ & 42.9 & 0 & 10 & 0 & NA & $47 a^{\star}$ & 22.7 & NA & $4.1^{*}$ & $2.4^{\star}$ & $0.9^{*}$ & $1.9^{*}$ \\
\hline & Controls & 60 & $44 / 16$ & 42.9 & 0 & 10 & 0 & & 20 & 22.1 & & 4.7 & 2.7 & 1.5 & 1.3 \\
\hline \multirow[t]{2}{*}{ Wang, $2014^{14}$} & DM§ & 51 & $43 / 8$ & 44.1 & 0 & NA & 0 & NA & NA & NA & 4.8 & 4.8 & 2.9 & 1.4 & $1.7^{*}$ \\
\hline & Controls & 51 & $43 / 8$ & 44.4 & 0 & & 0 & & & & 4.8 & 4.8 & 2.7 & 1.5 & 1.4 \\
\hline
\end{tabular}

${ }^{*} \mathrm{p}<0.05$; JDM: juvenile dermatomyositis;

fUnits are $\mathrm{mmol} / \mathrm{L}$ unless otherwise indicated and values are mean unless marked with $\sim=$ median.

fUntreated patients without hypertension, diabetes and cardiovascular heart disease.

$\S$ Patients without hypertension, diabetes and cardiovascular heart disease.

ПHypercholesterolemia.
ahypertriglyceridemia.

BMI, body mass index; DL, dyslipidaemia; DM, diabetes mellitus; DM: dermatomyositis; F/M, female/male; HDLc, high-density lipoprotein cholesterol; HT, hypertension; IIM, idiopathic

inflammatory myopathies; LDLc, low-density lipoprotein cholesterol; NA, not available; PG, plasma glucose; PM: polymyositis; TC, total cholesterol; TG, triglycerides. 


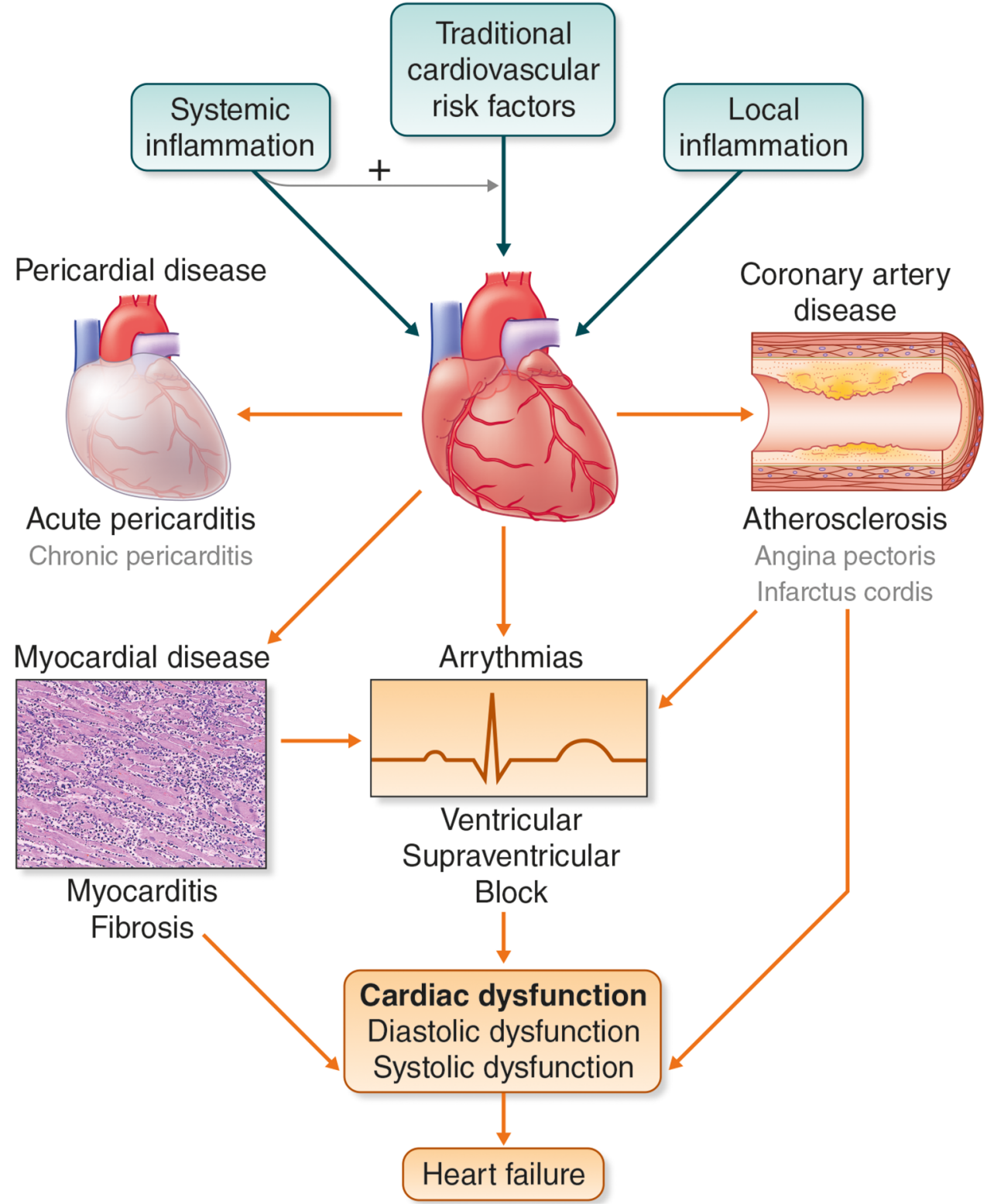

Figure 1 Traditional cardiovascular risk factors can cause cardiac disease in patients with IIM. Systemic and local inflammation may either have a direct effect on the myocardium or make the heart more susceptible to traditional risk factors. In the heart, disease can occur in the pericardium, coronary arteries or the myocardium, and arrhythmias can appear. Myocardial disease can result in diastolic or systolic dysfunction, and when clinical symptoms arise, the patient has developed heart failure. Myocardial disease may result in arrhythmias, or they can occur as a result of inflammation directly influencing cardiomyocyte function. Both arrhythmias and coronary artery disease, such as myocardial infarction, can directly result in heart failure.

failure. However, whereas a number of treatment options exist for systolic heart failure, no therapy has yet proven effective in diastolic heart failure. It is not known if diastolic dysfunction/heart failure can be prevented by early disease control.

\section{Coronary artery disease}

The suggested main mechanism of cardiovascular involvement in IIM is atherosclerosis in the coronary arteries (figure 1). In 2014, ${ }^{60}$ Ungprasert et al conducted a systematic review and meta-analysis of published observational studies addressing risk of coronary artery disease in adult onset IIM. Four studies, all using registry-based databases, were included ${ }^{4}$ 61-63 and demonstrated an increased risk of CAD with a pooled risk-ratio of 2.24 (CI 1.02 to 4.92). However, the only case-control study included in Ungprasert's review did not reveal an increased risk of CAD. Recently, a large population-based retrospective study with incident IIM cases from Canada reported an increased risk of myocardial infarction in dermatomyositis and polymyositis (nearly three and fourfold, respectively), after controlling for age, sex and use of corticosteroids and non-steroidal anti-inflammatory drugs. ${ }^{64}$ The risk for both groups was highest in the first year after diagnosis. 
Table 2 Echocardiographic findings of studies including tissue Doppler imaging

\begin{tabular}{|c|c|c|c|c|c|c|c|c|c|c|}
\hline Author, year & Group & $\begin{array}{l}\text { Participants } \\
\text { (n) }\end{array}$ & $\begin{array}{l}\text { F/M } \\
\text { (n) }\end{array}$ & $\begin{array}{l}\text { Age } \\
\text { (years) }\end{array}$ & $\begin{array}{l}\text { LV diastolic } \\
\text { dysfunction } \\
\text { (\%)† }\end{array}$ & $\begin{array}{c}\mathbf{e}^{\prime} \\
(\mathrm{cm} / \mathrm{s}) \dagger\end{array}$ & $\begin{array}{l}E / \mathbf{e}^{\prime} \\
\text { ratiot }\end{array}$ & $\begin{array}{l}\text { LV systolic } \\
\text { dysfunction } \\
\text { (\%)† }\end{array}$ & $\begin{array}{l}\text { LV EF } \\
(\%) \dagger\end{array}$ & $\begin{array}{l}\text { Long-axis } \\
\text { strain } \\
(\%) \dagger\end{array}$ \\
\hline \multirow[t]{2}{*}{ Diederichsen $2015^{21}$} & IIM+† & 14 & $8 / 6$ & 59.5 & 7 & 10.5 & 7.8 & 15 & 69 & NA \\
\hline & Controls & 14 & $8 / 6$ & 61.0 & 0 & 10.9 & 6.8 & 0 & 65 & \\
\hline \multirow[t]{2}{*}{ Diederichsen $2015^{18}$} & $\mathrm{PM} / \mathrm{DM}$ & 76 & $49 / 27$ & 60.0 & $63^{*}$ & $10.0^{*}$ & $8^{\star} \sim$ & 8 & 65 & NA \\
\hline & Controls & 48 & $32 / 16$ & 59.4 & 27 & 11.0 & $7 \sim$ & 2 & 65 & \\
\hline \multirow[t]{2}{*}{$\mathrm{Lu}, 2013^{15}$} & PM/DM $\ddagger$ & 46 & $31 / 15$ & 31.1 & 48 & $10.5^{\star}$ & $8.3^{*}$ & NA & 64.2 & NA \\
\hline & Controls & 21 & $11 / 10$ & 35.0 & NA & 12.7 & 6.8 & & 64.7 & \\
\hline Schwartz 2011 & JDM & 59 & $36 / 23$ & $21.5 \sim$ & $22^{*}$ & $11.3^{*}$ & $8.0^{*}$ & Yes§ & 63.2 & $16.6^{*}$ \\
\hline$+2014^{1617}$ & Controls & 59 & $36 / 23$ & $21.6 \sim$ & 0 & 12.4 & 7.1 & & 62.5 & 17.7 \\
\hline \multirow[t]{2}{*}{ Wang $2013^{57}$} & PM $\ddagger$ & 71 & $56 / 15$ & 46.9 & 59.2 & $7.5^{*}$ & $10.4^{*}$ & 0 & 67.7 & NA \\
\hline & Controls & 71 & $56 / 15$ & 46.2 & NA & 9.1 & 8.7 & 0 & 67.1 & \\
\hline \multirow[t]{2}{*}{ Wang, $2014^{14}$} & $\mathrm{DM} \neq$ & 51 & $43 / 8$ & 44.1 & $76.5^{\star}$ & $7.8^{*}$ & $9.9^{*}$ & 0 & 66.5 & NA \\
\hline & Controls & 51 & $43 / 8$ & 44.4 & 52.9 & 9.3 & 8.7 & 0 & 68.2 & \\
\hline
\end{tabular}

Values are mean unless marked with $\sim=$ median.

${ }^{*} \mathrm{p}<0.05$.

†Values are mean unless marked with $\sim=$ median.

†Patients without hypertension, diabetes and cardiovascular heart disease.

\#\#\#Newly diagnosed untreated patients without hypertension, diabetes and cardiovascular heart disease.

§Frequency of systolic dysfunction not presented.

††Newly diagnosed untreated patients.

DM, dermatomyositis; $e^{\prime}$, early diastolic tissue velocity; E, early diastolic transmitral flow; NA, not available; EF, ejection fraction; F/M, female/male; IIM, idiopathic inflammatory myopathy; JDM, juvenile dermatomyositis; LV, left ventricular; PM, polymyositis. 
Table 3 Methods of cardiac assessment in IIM

\begin{tabular}{|c|c|c|c|}
\hline Methods & Advantages & Disadvantages & Used in IIM \\
\hline ECG & $\begin{array}{l}\text { Can detect ST segment and T wave abnormalities, } \\
\text { arrhythmias and conduction abnormalities. May also give } \\
\text { indications of left ventricular hypertrophy. Readily available }\end{array}$ & $\begin{array}{l}\text { Some false positive and negative results. Clinical significance } \\
\text { often unclear. }\end{array}$ & $\begin{array}{l}\text { Many studies, } \\
\text { eg, }{ }^{6-8}\end{array}$ \\
\hline $\begin{array}{l}24 \text { hour } \\
\text { ECG/Holter monitoring }\end{array}$ & Can detect arrhythmias, heart rate variability and ischaemia & Requires more resources than standard ECG & 182170 \\
\hline Echo-cardiography & $\begin{array}{l}\text { Can assess wall thickness, size of the four chambers, valve } \\
\text { structure, systolic and diastolic function. Strain imaging and } \\
\text { tissue doppler are newer methods used to assess cardiac } \\
\text { function. }\end{array}$ & $\begin{array}{l}\text { Operator dependent. Low sensitivity for detection of myocardial } \\
\text { inflammation and fibrosis }\end{array}$ & $14-18 \quad 2157$ \\
\hline $\begin{array}{l}\text { Endomyocardial } \\
\text { biopsy }\end{array}$ & $\begin{array}{l}\text { Gold standard for detecting myocardial inflammation and } \\
\text { fibrosis. Remains a choice for selected patients based on } \\
\text { clinical indication. }\end{array}$ & $\begin{array}{l}\text { Unreliable if patchy lesions. Owing to high risk of } \\
\text { complications, biopsies are usually considered unethical in } \\
\text { studies }\end{array}$ & $\begin{array}{l}\text { No clinical } \\
\text { data in IIM }\end{array}$ \\
\hline Cardiac MR (CMR) & $\begin{array}{l}\text { Can image cardiac structure and function from any projection. } \\
\text { Primary imaging modality when diffuse or localised myocardial } \\
\text { fibrosis (late gadolinium enhancement or T1 mapping), or } \\
\text { myocarditis (T weighted, T1 mapping or early gadolinium } \\
\text { enhancement) is suspected. }\end{array}$ & $\begin{array}{l}\text { Time-consuming } \\
\text { Requires expensive technology } \\
\text { Limited availability }\end{array}$ & 19216768 \\
\hline $\begin{array}{l}\text { Cardiac }{ }^{99 \mathrm{~m}} \mathrm{Tc}-\mathrm{PYP} \\
\text { scintigraphy }\end{array}$ & $\begin{array}{l}\text { Can detect and quantify inflammation of the myocardium by } \\
\text { increased }{ }^{99 \mathrm{~m}} \mathrm{TC} \text {-PYP uptake }\end{array}$ & $\begin{array}{l}\text { Requires supplementary CT to image structures. } \\
\text { Time-consuming. Limited availability }\end{array}$ & 182021 \\
\hline$\overline{\mathrm{CT}}$ & $\begin{array}{l}\text { Can assess coronary artery calcification (CAC score). Good } \\
\text { negative predictive value. }\end{array}$ & Radiation & 22 \\
\hline Creatine Kinase (CK) & $\begin{array}{l}\text { Available and cheap } \\
\text { A CK-MB/CK total—ratio }>3 \% \text { usually indicates cardiac } \\
\text { damage }\end{array}$ & $\begin{array}{l}\text { In IIM, this ratio might be elevated even without cardiac } \\
\text { involvement }\end{array}$ & $\begin{array}{l}95, \text { used in } \\
\text { most IIM } \\
\text { studies }\end{array}$ \\
\hline $\begin{array}{l}\text { Troponins } \\
\text { Troponin I } \\
\text { Troponin T }\end{array}$ & $\begin{array}{l}\text { Serum markers specific to myocardial damage, and are } \\
\text { therefore preferred to detect cardiac involvement. Troponin I } \\
\text { most specific to the myocardium }\end{array}$ & $\begin{array}{l}\text { Expressed in fetal skeletal muscle and in healthy or } \\
\text { regenerating adult skeletal muscle. Both troponin-T and } \\
\text { troponin-I can be elevated in the presence of renal failure }\end{array}$ & $\begin{array}{ll}79 \text { 95-98 } \\
\end{array}$ \\
\hline $\begin{array}{l}\text { B-type natriuretic } \\
\text { peptide } \\
\text { (BNP) }\end{array}$ & Marker of heart failure & Can be elevated in the presence of renal failure & No data in IIM \\
\hline
\end{tabular}


For IBM, few data exist. In a recent Norwegian population-based study with a mean disease duration of 5.5 years, the mortality due to heart failure and myocardial infarction was higher in those with IBM $(8 / 31$, $26 \%$ ) than in those with PM and DM $(4 / 56,7 \%)$. However, the patients with IBM were older $(66.9(0.9)$ versus 53.2 (1.5) years). ${ }^{31}$ To the best of our knowledge, no studies address the relationship between JDM and coronary artery disease.

An accelerated process of atherosclerosis is evident in patients with IIM, and seems to be an important aspect in the development of cardiac involvement, ${ }^{22} 4165$ as it is in $\mathrm{RA}^{66}$ and SLE. ${ }^{3}$ In addition, the higher burden of atherosclerosis appears to be associated with the increased presence of traditional cardiovascular risk factors. ${ }^{22}$ Taken together, clinicians should be aware of symptoms that can be caused by coronary artery disease in patients with IIM.

\section{Myocarditis}

Myocarditis is highlighted as a probable and intriguing mechanism for cardiac dysfunction in IIM, since inflammation similar to that seen in skeletal muscle also can occur in heart muscle (figure 1). Through a comprehensive literature search in 2011, Gupta $e t a l^{24}$ found cardiac biopsy data on 68 patients with IIM (including patients with juvenile onset disease) almost exclusively autopsy based. In 1979 and 1982, two series showed myocarditis in 6 of $20(30 \%)$ and 4 of $16(25 \%)$ patients with DM and $\mathrm{PM}$, respectively. ${ }^{12}{ }^{13}$ Mononuclear cell infiltrates were localised to the endomysium and perivascular areas of the heart muscle, with or without small vessel disease and replacement fibrosis; this resembled the inflammation in skeletal muscle. Infiltrates were also found in the conduction system. ${ }^{13}$ The remaining of the 68 patients reviewed by Gupta $e t$ al were described in three studies and eight case reports. ${ }^{24}$ Nevertheless, among these unsystematically selected patients, as many as $38 \%$ had myocarditis and $41 \%$ myocardial fibrosis, suggesting a possible involvement of the heart muscle in patients with IIM.

CMR gives the opportunity of non-invasive investigation of cardiac inflammation. Recent uncontrolled data showed a high proportion (62-75\%) of patients with IIM with pathological myocardial enhancement, resembling inflammation and fibrosis. ${ }^{19} 6768$ Also, in a recent case report, MRI mapping techniques detected myocardial oedema. ${ }^{69}{ }^{99 \mathrm{~m}}$ Technetium pyrophosphate $\left({ }^{99 \mathrm{~m}} \mathrm{Tc}-\mathrm{PYP}\right)$ scintigraphy is also capable of detecting cardiac muscle involvement, and increased myocardium PYP-uptake, indicative of inflammation, was observed in 57\% of patients with $\mathrm{PM} / \mathrm{DM}{ }^{20}$ Two patients with high PYP-uptake and corresponding left ventricular dysfunction died. Autopsy showed inflammation, degeneration and fibrosis of the myocardium in accordance with PYP scintigraphy results. A controlled study has recently established a correlation between the magnitudes of myocardium PYP-uptake and diastolic dysfunction of the heart, which strongly suggests inflammation to be a significant contributor to cardiac involvement in IIM. ${ }^{18}$ However, these findings were subclinical and further prospective studies are desirable. We suggest considering MRI and/ or $\left({ }^{99 \mathrm{~m}}\right.$ Tc-PYP $)$ scintigraphy as part of the clinical evaluation of patients with IIM if myocarditis is suspected.

\section{Arrhythmia and heart rate variability}

Conduction abnormalities on ECG is the most prevalent evidence of cardiac involvement reported in IIM (figure 1). In the late 1970s/1980s, several uncontrolled studies reported ECG changes like non-specific ST-T wave changes, conduction abnormalities or premature ventricular beats in $32-52 \%$ of patients with IIM (13-77 patients) without clinical signs of cardiac disease.$^{6-8} 34$ In an autopsy study, as many as 13/18 (72\%) had ECG changes assessed retrospectively. ${ }^{12}$ In a Danish study from 2015, patients with adult PM/DM had longer QTc intervals compared with controls, ${ }^{18}$ even though the prevalence of pathological QTc was comparable. Pathologically prolonged QTc is a known predictor for cardiac arrhythmias and sudden death. Further studies are needed to clarify the clinical relevance of longer QTc in IIM. A recent Norwegian study demonstrated that patients with JDM examined after a median disease duration of 17 years had more prevalent ECG abnormalities 23/59 (39\%) compared to age-matched and sex-matched controls. ${ }^{16}$

In a subset of the same Norwegian JDM cohort (after a median disease duration of 13.5 years), heart rate variability (HRV) was lower in patients than controls assessed by Holter ECG. ${ }^{70}$ Low HRV indicates autonomic dysfunction, and is associated with increased risk of cardiac events and death in the general population. ${ }^{71}$ Autonomic dysfunction by HRV has, to the best of our knowledge, not been investigated in the adult onset IIM population.

Taken together, these findings indicate that even if the detected ECG abnormalities in IIM are often subclinical, the associated cardiac involvement can lead to arrhythmias or sudden death.

\section{Pericarditis}

Pericarditis in IIM is mostly asymptomatic and haemodynamically insignificant. It has been found in $4-25 \%$ of adult onset patients with $\mathrm{IIM}^{8-11}$ and $12-15 \%$ of patients with JDM during the disease course. ${ }^{16}{ }^{72}$ However, it may be more common in subgroups of patients with antisynthetase syndrome (ASS). In a European multicentre study, 9 of 18 anti-PL-7-positive patients (50\%) had pericardial effusion during the disease course. ${ }^{73}$

\section{Pulmonary hypertension}

In IIM, pulmonary hypertension $(\mathrm{PH})$ is probably infrequent in the absence of ILD or antisynthetase autoantibodies, but has not been systematically described and data are mostly limited to case reports or case series. ${ }^{74}$ The most effective screening method is echocardiography, but PH must be confirmed by right heart catheterisation. $\mathrm{PH}$ has been confirmed in $8-9 \%$ of patients with ASS in two retrospective series, ${ }^{75} \quad 76$ mostly 
secondary to ILD. The presence of $\mathrm{PH}$ dramatically worsened the prognosis, with a 3 -year survival rate of $58 \%{ }^{75}$ These findings support that routine screening for $\mathrm{PH}$ should be performed by echocardiography in patients with ASS at diagnosis and then annually as recommended in patients with systemic sclerosis. ${ }^{77}$ Screening is important since $\mathrm{PH}$ can lead to right ventricular failure, a life-threatening complication.

\section{METHODS OF CARDIAC ASSESSMENTS}

There are several methods available for assessment of cardiac structure and function. ${ }^{78}$ The most important methods, their advantages and limitations, as well as an overview of the methods used in IIMs, are shown in table 3. We would like to highlight the opportunities offered by new echocardiographic methods and by CMR, making detection of subclinical cardiac dysfunction possible. Also, cardiac troponin I appears to be specific to the myocardium, while troponin $\mathrm{T}$ is also expressed in skeletal muscle. Thus, troponin $\mathrm{T}$ can be elevated in IIM in the absence of myocardial involvement. ${ }^{79}$

\section{PATHOPHYSIOLOGY}

Different mechanisms are suspected in the development of cardiac involvement in IIM. Recently, Wang et al found dyslipidaemia in newly diagnosed, untreated patients with $\mathrm{PM}^{39}$ and with $\mathrm{DM},{ }^{38}$ with lower highdensity lipoprotein cholesterol (HDL-c) and higher triglycerides and total-/HDL cholesterol (TC/HDL) ratio than matched controls. High TC/HDL ratio is a predictor of ischaemic heart disease, superior to other lipid parameters such as TC and HDL/low-density lipoprotein (LDL) ${ }^{80}$ Another controlled study of younger patients with JDM (median age 21.5 years), seen at long-term (17 years) follow-up, had similar findings of dyslipidaemia. ${ }^{16}$ High TC/HDL ratio and total cholesterol in the upper normal range correlated with subclinical cardiac dysfunction in those with active disease. ${ }^{42}$ This could indicate a lowered threshold of harmful cholesterol associated effects in active disease. The 'lipid paradox' with increased susceptibility to atherosclerosis with low cholesterol levels is even better documented in RA. ${ }^{81} 82$

Autopsy studies of patients with IIM have shown evidence of inflammatory cells in the myocardium, ${ }^{12} 18$ indicating the presence of myocarditis. Myocarditis can lead to myocardial fibrosis, which again causes stiffening of the ventricles (diastolic dysfunction) or arrhythmias (figure 1). In the general population, increased serum levels of proinflammatory cytokines are seen with increasing New York Heart Association-class ${ }^{83}$ and thus the degree of heart failure. In a cohort of patients with JDM, MCP-1 and CCL11 (eotaxin) were elevated and associated with cardiac dysfunction. ${ }^{42}$ MCP-1 is known to induce hypertrophy and myocardial fibrosis in rodents ${ }^{83}$ and CCL11 fibrosis and myocardial stiffness in rats. ${ }^{84}$

Myositis specific and associated autoantibodies (MSA and MAA) are strong diagnostic tools in IIM, which can define phenotypes, including lung involvement. ${ }^{85}$ An association between antisignalling recognition particle (anti-SRP) and cardiac disease has been proposed, but evidence is weak in adult IIM. ${ }^{24}$ However, in juvenile IIM, the presence of anti-SRP was associated with more frequent abnormal ECG and by echocardiography. ${ }^{86}$ In a recent Danish study, the presence of a MSA or MAA was associated with diastolic dysfunction, although a relationship between specific autoantibodies and diastolic dysfunction was not observed. ${ }^{18}$

\section{PREVENTION, DIAGNOSTIC WORK-UP/FOLLOW-UP AND MANAGEMENT \\ Prevention}

Treatment of dyslipidaemia in patients with IIM is complex. Statins can prevent cardiovascular disease in the general population. In rare cases, statins can be the main cause of disease, that is, statin-associated autoimmune necrotising myopathy. ${ }^{87} \mathrm{~A}$ recent study performed by the International Myositis Assessment and Clinical Studies Group (IMACS) on the use of lipid-lowering therapy in patients with IIM showed that $76 \%$ of the IIM specialists prescribed lipid-lowering drugs, mostly statins (93\%). ${ }^{88}$ Approximately $10 \%$ of the patients developed worsening of their muscle symptoms, of which some were reversible on discontinuation of statin treatment. With the literature available, patients with IIM should follow the same recommendations for cardiovascular risk stratification and prevention as for the corresponding general population. ${ }^{89} 90$ Thus, in IIM, statins should be used with careful monitoring as they may worsen muscle symptoms that can be misinterpreted as a relapse of myositis. Also, clinicians should keep in mind the lipid paradox described above.

\section{Diagnostic workup and follow-up}

If clinical or subclinical cardiac involvement is suspected based on cardiac symptoms and/or basic cardiac measurements (physical examination, troponin, ECG, etc), a cardiologist should be involved. A low threshold for echocardiographic examination should be observed. To evaluate systolic involvement, we recommend assessing long axis strain (EF is not sensitive enough), and to evaluate diastolic involvement we recommend $\mathrm{E} / \mathrm{e}$. If available, we suggest considering MRI and/or $\left({ }^{99 \mathrm{~m}} \mathrm{Tc}-\mathrm{PYP}\right)$ scintigraphy as part of the clinical evaluation of patients with IIM if myocarditis is suspected.

As a follow-up, it seems reasonable to do yearly ECG, since ECG changes are the most prevalent evidence of cardiac involvement reported in IIM. Specifically, attention should be paid to prolongation of the QTc interval, which in turn might call for Holter monitoring to exclude clinically significant ventricular arrhythmia.

\section{Management}

Currently, there are no specific guidelines available for treatment of heart involvement in myositis. Although 
inflammatory changes within the myocardium are thought to be the cause of reported cardiac dysfunction, the impact of immunosuppressive therapy is unknown. However, it is reasonable to assume that an early and sustained reduction in inflammation might reduce the risk of developing diffuse interstitial myocardial fibrosis, which is important since inflammation is treatable, while fibrosis is thought to be irreversible.

In several case reports, successful pharmacological treatment of arrhythmia, conduction disorders and heart failure in children and adults with myositis are reported. ${ }^{11} 48{ }^{91}$ However, it is hard to decide the effect of the immunosuppressive treatment alone, since these patients also received antiarrhythmic drugs and heart failure management depending on their symptoms. Three studies including 20-44 patients with adult onset DM/PM show an effect of glucocorticoids plus other immunosuppressive drugs on clinical or subclinical heart involvement in the majority of patients. ${ }^{116892}$

Importantly, heart disease can also occur any time during the disease course under immunosuppressive treatment, ${ }^{93}$ and even in patients in remission. ${ }^{94}$

Based on case reports, glucocorticoids, either alone or in combination with other immunosuppressive drugs, are cornerstones in the treatment of myocarditis. In addition to immunosuppressive therapy, management of cardiac involvement may require individually tailored cardiac specific therapy.

\section{CONCLUDING REMARKS}

Similar to other rheumatic diseases, IIM is associated with an increased risk of cardiac disease: however, the prevalence still remains uncertain. The main mechanisms responsible seem to be atherosclerosis and myocarditis. New methods of cardiac imaging with ever increasing sensitivity enable us to detect subtle changes of cardiac function. As physicians, we must use this new insight to give patients with IIM optimal cardiac care and preventive treatment; however, consensus guidelines for this do not yet exist. Also, this new insight challenges us to determine which findings have clinical significance and, perhaps, which have not. Therefore, longitudinal follow-up of patients with IIM with recording of clinical manifestations of heart involvement is needed. Since these are rare diseases, international collaboration is essential. To support such collaboration, the Euromyositis Register has been developed to facilitate longitudinal follow-up of outcome in patients with IIM, including organ-specific morbidity (http://www.euromyositis.net.eu).

\footnotetext{
Author affiliations

${ }^{1}$ Department of Rheumatology, Oslo University Hospital-Rikshospitalet, Oslo, Norway

${ }^{2}$ Institute for Experimental Medical Research, Oslo University Hospital-Ullevål and University of Oslo, Oslo, Norway

${ }^{3}$ Department of Rheumatology, Odense University Hospital, Odense, Denmark

${ }^{4}$ Rheumatology Unit, Department of Medicine, Solna, Karolinska Institutet,

Rheumatology Unit, Karolinska University Hospital, Stockholm, Sweden
}

${ }^{5}$ Department of Cardiology, Oslo University Hospital-Ullevål, Oslo, Norway ${ }^{6}$ Norwegian National Advisory Unit on Rheumatic Diseases in Children and Adolescents, Department of Rheumatology, Oslo University Hospital, Rikshospitalet, Oslo, Norway

Funding TS and IS are supported by KG Jebsen Cardiac Research Center and Center for Heart Failure Research, University of Oslo, Oslo, Norway.

Competing interests None declared.

Provenance and peer review Commissioned; externally peer reviewed.

Data sharing statement No additional data are available.

Open Access This is an Open Access article distributed in accordance with the Creative Commons Attribution Non Commercial (CC BY-NC 4.0) license, which permits others to distribute, remix, adapt, build upon this work noncommercially, and license their derivative works on different terms, provided the original work is properly cited and the use is non-commercial. See: http:// creativecommons.org/licenses/by-nc/4.0/

\section{REFERENCES}

1. Solomon DH, Goodson NJ, Katz JN, et al. Patterns of cardiovascular risk in rheumatoid arthritis. Ann Rheum Dis 2006;65:1608-12.

2. Symmons DP, Gabriel SE. Epidemiology of CVD in rheumatic disease, with a focus on RA and SLE. Nat Rev Rheumatol 2011;7:399-408.

3. Badui E, Garcia-Rubi D, Robles E, et al. Cardiovascular manifestations in systemic lupus erythematosus. Prospective study of 100 patients. Angiology 1985;36:431-41.

4. Zöller B, Li X, Sundquist J, et al. Risk of subsequent coronary heart disease in patients hospitalized for immune-mediated diseases: a nationwide follow-up study from Sweden. PLOS ONE 2012;7:e33442.

5. Zöller B, Li X, Sundquist J, et al. Risk of subsequent ischemic and hemorrhagic stroke in patients hospitalized for immune-mediated diseases: a nationwide follow-up study from Sweden. BMC Neurol 2012;12:41.

6. Stern R, Godbold JH, Chess Q, et al. ECG abnormalities in polymyositis. Arch Intern Med 1984;144:2185-9.

7. Sharratt GP, Danta G, Carson PH. Cardiac abnormality in polymyositis. Ann Rheum Dis 1977;36:575-8.

8. Gottdiener JS, Sherber HS, Hawley RJ, et al. Cardiac manifestations in polymyositis. Am J Cardiol 1978;41:1141-9.

9. Gonzalez-Lopez L, Gamez-Nava JI, Sanchez L, et al. Cardiac manifestations in dermato-polymyositis. Clin Exp Rheumatol 1996;14:373-9.

10. Taylor AJ, Wortham DC, Burge JR, et al. The heart in polymyositis: a prospective evaluation of 26 patients. Clin Cardiol 1993;16:802-8.

11. Askari AD, Huettner TL. Cardiac abnormalities in polymyositis/ dermatomyositis. Semin Arthritis Rheum 1982;12:208-19.

12. Denbow CE, Lie JT, Tancredi RG, et al. Cardiac involvement in polymyositis: a clinicopathologic study of 20 autopsied patients. Arthritis Rheum 1979;22:1088-92.

13. Haupt HM, Hutchins GM. The heart and cardiac conduction system in polymyositis-dermatomyositis: a clinicopathologic study of 16 autopsied patients. Am J Cardiol 1982;50:998-1006.

14. Wang $\mathrm{H}$, Liu HX, Wang YL, et al. Left ventricular diastolic dysfunction in patients with dermatomyositis without clinically evident cardiovascular disease. J Rheumatol 2014;41:495-500.

15. Lu Z, Wei Q, Ning Z, et al. Left ventricular diastolic dysfunctionearly cardiac impairment in patients with polymyositis/ dermatomyositis: a tissue Doppler imaging study. J Rheumatol 2013;40:1572-7.

16. Schwartz T, Sanner H, Husebye T, et al. Cardiac dysfunction in juvenile dermatomyositis: a case-control study. Ann Rheum Dis 2011;70:766-71.

17. Schwartz T, Sanner H, Gjesdal O, et al. In juvenile dermatomyositis, cardiac systolic dysfunction is present after long-term follow-up and is predicted by sustained early skin activity. Ann Rheum Dis 2014;73:1805-10.

18. Diederichsen LP, Simonsen JA, Diederichsen AC, et al. Cardiac Abnormalities in Adult Patients With Polymyositis or Dermatomyositis as Assessed by Noninvasive Modalities. Arthritis Care Res (Hoboken) 2016;68:1012-20.

19. Rosenbohm A, Buckert D, Gerischer N, et al. Early diagnosis of cardiac involvement in idiopathic inflammatory myopathy by cardiac magnetic resonance tomography. J Neurol 2015;262:949-56.

20. Buchpiguel CA, Roizemblatt S, Pastor EH, et al. Cardiac and skeletal muscle scintigraphy in dermato- and polymyositis: clinical implications. Eur J Nucl Med 1996;23:199-203. 
21. Diederichsen LP, Simonsen JA, Diederichsen AC, et al. Cardiac abnormalities assessed by non-invasive techniques in patients with newly diagnosed idiopathic inflammatory myopathies. Clin Exp Rheumatol 2015;33:706-14.

22. Diederichsen LP, Diederichsen AC, Simonsen JA, et al. Traditional cardiovascular risk factors and coronary artery calcification in adults with polymyositis and dermatomyositis: a Danish multicenter study. Arthritis Care Res (Hoboken) 2015;67:848-54.

23. Lundberg IE. The heart in dermatomyositis and polymyositis. Rheumatology (Oxford) 2006;45(Suppl 4):iv18-21.

24. Gupta R, Wayangankar SA, Targoff IN, et al. Clinical cardiac involvement in idiopathic inflammatory myopathies: a systematic review. Int J Cardiol 2011;148:261-70.

25. Marie I. Morbidity and mortality in adult polymyositis and dermatomyositis. Curr Rheumatol Rep 2012;14:275-85.

26. Dankó K, Ponyi A, Constantin T, et al. Long-term survival of patients with idiopathic inflammatory myopathies according to clinical features: a longitudinal study of 162 cases. Medicine (Baltimore) 2004;83:35-42.

27. Sultan SM, loannou $\mathrm{Y}$, Moss $\mathrm{K}$, et al. Outcome in patients with idiopathic inflammatory myositis: morbidity and mortality. Rheumatology (Oxford) 2002;41:22-6.

28. Bohan A, Peter JB, Bowman RL, et al. Computer-assisted analysis of 153 patients with polymyositis and dermatomyositis. Medicine (Baltimore) 1977;56:255-86.

29. Rose AL, Walton JN. Polymyositis: a survey of 89 cases with particular reference to treatment and prognosis. Brain 1966;89:747-68.

30. Airio A, Kautiainen $\mathrm{H}$, Hakala M. Prognosis and mortality of polymyositis and dermatomyositis patients. Clin Rheumatol 2006;25:234-9.

31. Dobloug GC, Garen T, Brunborg C, et al. Survival and cancer risk in an unselected and complete Norwegian idiopathic inflammatory myopathy cohort. Semin Arthritis Rheum 2015;45:301-8.

32. Taborda AL, Azevedo P, Isenberg DA. Retrospective analysis of the outcome of patients with idiopathic inflammatory myopathy: a long-term follow-up study. Clin Exp Rheumatol 2014;32:188-93.

33. Limaye $\mathrm{V}$, Hakendorf $\mathrm{P}$, Woodman RJ, et al. Mortality and its predominant causes in a large cohort of patients with biopsy-determined inflammatory myositis. Intern Med $J$ 2012;42:191-8

34. Hochberg MC, Feldman D, Stevens MB. Adult onset polymyositis/ dermatomyositis: an analysis of clinical and laboratory features and survival in 76 patients with a review of the literature. Semin Arthritis Rheum 1986;15:168-78.

35. Huber AM, Mamyrova G, Lachenbruch PA, et al. Early illness features associated with mortality in the juvenile idiopathic inflammatory myopathies. Arthritis Care Res (Hoboken) 2014;66:732-40.

36. de Moraes MT, de Souza FH, de Barros TB, et al. Analysis of metabolic syndrome in adult dermatomyositis with a focus on cardiovascular disease. Arthritis Care Res (Hoboken) 2013;65:793-9.

37. de Souza FH, Shinjo SK. The high prevalence of metabolic syndrome in polymyositis. Clin Exp Rheumatol 2014;32:82-7.

38. Wang $\mathrm{H}$, Tang $\mathrm{J}$, Chen $\mathrm{X}$, et al. Lipid profiles in untreated patients with dermatomyositis. J Eur Acad Dermatol Venereol 2013;27:175-9.

39. Wang $\mathrm{H}$, Cai $\mathrm{Y}$, Cai $\mathrm{L}$, et al. Altered lipid levels in untreated patients with early polymyositis. PLOS ONE 2014;9:e89827.

40. Coyle $\mathrm{K}$, Rother KI, Weise $\mathrm{M}$, et al. Metabolic abnormalities and cardiovascular risk factors in children with myositis. J Pediatr 2009;155:882-7.

41. Eimer MJ, Brickman WJ, Seshadri R, et al. Clinical status and cardiovascular risk profile of adults with a history of juvenile dermatomyositis. J Pediatr 2011;159:795-801.

42. Schwartz T, Sjaastad I, Flatø B, et al. In active juvenile dermatomyositis, elevated eotaxin and MCP-1 and cholesterol levels in the upper normal range are associated with cardiac dysfunction. Rheumatology (Oxford) 2014;53:2214-22.

43. Choy E, Ganeshalingam K, Semb AG, et al. Cardiovascular risk in rheumatoid arthritis: recent advances in the understanding of the pivotal role of inflammation, risk predictors and the impact of treatment. Rheumatology (Oxford) 2014;53:2143-54.

44. Gustafsson JT, Svenungsson E. Definitions of and contributions to cardiovascular disease in systemic lupus erythematosus. Autoimmunity 2014:47:67-76.

45. Nagueh SF, Smiseth OA, Appleton CP, et al. Recommendations for the evaluation of left ventricular diastolic function by echocardiography: an update from the American Society of
Echocardiography and the European Association of Cardiovascular Imaging. J Am Soc Echocardiogr 2016;29:277-314.

46. Odabasi Z, Yapundich R, Oh SJ. Polymyositis presenting with cardiac manifestations: report of two cases and review of the literature. Clin Neurol Neurosurg 2010;112:160-3.

47. Ohata $\mathrm{S}$, Shimada $\mathrm{T}$, Shimizu $\mathrm{H}$, et al. Myocarditis associated with polymyositis diagnosed by gadolinium-DTPA enhanced magnetic resonance imaging. J Rheumatol 2002;29:861-2.

48. Sharma K, Orbai AM, Desai D, et al. Brief report: antisynthetase syndrome-associated myocarditis. J Card Fail 2014;20:939-45.

49. Lynch PG. Cardiac involvement in chronic polymyositis. Br Heart $J$ 1971;33:416-19.

50. Rasmussen LH, Madsen HN, Ladefoged SD. Creatine phosphokinase $\mathrm{MB}$ and lactate dehydrogenase isoenzyme 1 in polymyositis. Scand J Rheumatol 1985;14:427-30.

51. Peregud-Pogorzelska M, Kazmierczak J, Brzosko M. Rhythm disturbances in the form of atrial tachycardia in a female patient with polymyositis-a case report. Angiology 2006;57:391-4.

52. Sénéchal $M$, Créte $M$, Couture $C$, et al. Myocardial dysfunction in polymyositis. Can J Cardiol 2006;22:869-71.

53. Rechavia E, Rotenberg Z, Fuchs J, et al. Polymyositic heart disease. Chest 1985;88:309-11.

54. Behan WM, Aitchison M, Behan PO. Pathogenesis of heart block in a fatal case of dermatomyositis. Br Heart J 1986;56:479-82.

55. Afzal A, Higgins RS, Philbin EF. Heart transplant for dilated cardiomyopathy associated with polymyositis. Heart 1999;82:e4.

56. Mavrakanas TA, Lobrinus A, Berdagué $\mathrm{P}$, et al. Severe mitral valve regurgitation in polymyositis. $J$ Clin Rheumatol 2012;18:367-9.

57. Wang $\mathrm{H}$, Liu $\mathrm{H}, \mathrm{Yu} \mathrm{X}$, et al. Left ventricle diastolic function in patients with polymyositis. Int $J$ Cardiol 2013;168:4311-12.

58. Vinereanu D, Nicolaides E, Tweddel AC, et al. "Pure" diastolic dysfunction is associated with long-axis systolic dysfunction. Implications for the diagnosis and classification of heart failure. Eur J Heart Fail 2005;7:820-8.

59. Baicu CF, Zile MR, Aurigemma GP, et al. Left ventricular systolic performance, function, and contractility in patients with diastolic heart failure. Circulation 2005;111:2306-12.

60. Ungprasert P, Suksaranjit P, Spanuchart I, et al. Risk of coronary artery disease in patients with idiopathic inflammatory myopathies: a systematic review and meta-analysis of observational studies. Semin Arthritis Rheum 2014;44:63-7.

61. Tisseverasinghe A, Bernatsky S, Pineau CA. Arterial events in persons with dermatomyositis and polymyositis. $J$ Rheumatol 2009;36:1943-6.

62. Lai YT, Dai YS, Yen MF, et al. Dermatomyositis is associated with an increased risk of cardiovascular and cerebrovascular events: a Taiwanese population-based longitudinal follow-up study. Br J Dermatol 2013;168:1054-9.

63. Linos E, Fiorentino D, Lingala B, et al. Atherosclerotic cardiovascular disease and dermatomyositis: an analysis of the Nationwide Inpatient Sample survey. Arthritis Res Ther 2013;15:R7.

64. Rai SK, Choi HK, Sayre EC, et al. Risk of myocardial infarction and ischaemic stroke in adults with polymyositis and dermatomyositis: a general population-based study. Rheumatology (Oxford) 2016:55:461-9.

65. Vincze M, Dér H, Kerekes G, et al. Decreased flow-mediated dilatation with increased arterial stiffness and thickness as early signs of atherosclerosis in polymyositis and dermatomyositis patients. Clin Rheumatol 2014;33:1635-41.

66. Maradit-Kremers H, Nicola PJ, Crowson CS, et al. Cardiovascular death in rheumatoid arthritis: a population-based study. Arthritis Rheum 2005;52:722-32.

67. Mavrogeni S, Douskou M, Manoussakis MN. Contrast-enhanced CMR imaging reveals myocardial involvement in idiopathic inflammatory myopathy without cardiac manifestations. JACC Cardiovasc Imaging 2011;4:1324-5.

68. Mavrogeni S, Bratis K, Karabela G, et al. Myocarditis during acute inflammatory myopathies: evaluation using clinical criteria and cardiac magnetic resonance imaging. Int J Cardiol 2013;164:e3-4.

69. Sado DM, Kozor R, Corr L, et al. Global myocardial edema in antisynthetase syndrome detected by cardiovascular magnetic resonance mapping techniques. Circulation 2016;133:e25-6.

70. Barth Z, Nomeland Witczak B, Schwartz T, et al. In juvenile dermatomyositis, heart rate variability is reduced, and associated with both cardiac dysfunction and markers of inflammation: a cross-sectional study median 13.5 years after symptom onset. Rheumatology (Oxford) 2016;55:535-43.

71. Xhyheri $\mathrm{B}$, Manfrini $\mathrm{O}$, Mazzolini $\mathrm{M}$, et al. Heart rate variability today. Prog Cardiovasc Dis 2012;55:321-31. 
72. Sallum AM, Pivato FC, Doria-Filho U, et al. Risk factors associated with calcinosis of juvenile dermatomyositis. J Pediatr (Rio J) 2008;84:68-74.

73. Labirua-Iturburu A, Selva-O'Callaghan A, Vincze M, et al. Anti-PL-7 (anti-threonyl-tRNA synthetase) antisynthetase syndrome: clinical manifestations in a series of patients from a European multicenter study (EUMYONET) and review of the literature. Medicine (Baltimore) 2012;91:206-11.

74. Lega JC, Reynaud Q, Belot A, et al. Idiopathic inflammatory myopathies and the lung. Eur Respir Rev 2015;24:216-38.

75. Hervier B, Meyer A, Dieval C, et al. Pulmonary hypertension in antisynthetase syndrome: prevalence, aetiology and survival. Eur Respir J 2013;42:1271-82.

76. Cavagna L, Nuño L, Scirè CA, et al. Clinical spectrum time course in anti Jo-1 positive antisynthetase syndrome: results from an international retrospective multicenter study. Medicine (Baltimore) 2015;94:e1144.

77. Nakanishi N, European Society of Cardiology, European Respiratory Society. 2009 ESC/ERS pulmonary hypertension guidelines and connective tissue disease. Allergol Int 2011;60:419-24.

78. Mann DL, Zipes DP, Libby $\mathrm{P}$, et al. Braunwald's heart disease: a textbook of cardiovascular medicine. 10th edn. Saunders, 2014.

79. Hughes $\mathrm{M}$, Lilleker JB, Herrick $\mathrm{AL}$, et al. Cardiac troponin testing in idiopathic inflammatory myopathies and systemic sclerosis-spectrum disorders: biomarkers to distinguish between primary cardiac involvement and low-grade skeletal muscle disease activity. Ann Rheum Dis 2015;74:795-8.

80. Lewington S, Whitlock G, Clarke R, et al. Prospective Studies Collaboration. Blood cholesterol and vascular mortality by age, sex, and blood pressure: a meta-analysis of individual data from 61 prospective studies with 55,000 vascular deaths. Lancet 2007;370:1829-39.

81. Choy E, Sattar N. Interpreting lipid levels in the context of high-grade inflammatory states with a focus on rheumatoid arthritis: a challenge to conventional cardiovascular risk actions. Ann Rheum Dis 2009;68:460-9.

82. Amezaga UM, Suarez-Almazor ME. Lipid paradox in rheumatoid arthritis: changes with rheumatoid arthritis therapies. CurrRheumatolRep 2012;14:428-37.

83. Gullestad L, Ueland T, Vinge LE, et al. Inflammatory cytokines in heart failure: mediators and markers. Cardiology 2012;122:23-35.

84. Zweifel M, Matozan K, Dahinden C, et al. Eotaxin/CCL11 levels correlate with myocardial fibrosis and mast cell density in native and transplanted rat hearts. Transplant Proc 2010;42:2763-6.
85. Ghirardello A, Borella E, Beggio M, et al. Myositis autoantibodies and clinical phenotypes. Auto Immun Highlights 2014;5:69-75.

86. Rider LG, Shah M, Mamyrova G, et al. The myositis autoantibody phenotypes of the juvenile idiopathic inflammatory myopathies. Medicine (Baltimore) 2013;92:223-43.

87. Christopher-Stine L, Casciola-Rosen LA, Hong G, et al. A novel autoantibody recognizing $200-k d$ and $100-k d$ proteins is associated with an immune-mediated necrotizing myopathy. Arthritis Rheum 2010;62:2757-66.

88. Charles-Schoeman C, Amjadi SS, Paulus HE, et al. Treatment of dyslipidemia in idiopathic inflammatory myositis: results of the International Myositis Assessment and Clinical Studies Group survey. Clin Rheumatol 2012;31:1163-8.

89. Erbel R, Möhlenkamp S, Moebus S, et al. Coronary risk stratification, discrimination, and reclassification improvement based on quantification of subclinical coronary atherosclerosis: the Heinz Nixdorf Recall study. J Am Coll Cardiol 2010;56:1397-406.

90. Andrus B, Lacaille D. 2013 ACC/AHA guideline on the assessment of cardiovascular risk. J Am Coll Cardiol 2014;63:2886.

91. Jindal G, Singh S, Suri D, et al. Recurrent ventricular tachycardia in a child with juvenile dermatomyositis - an unusual association. Int $J$ Rheum Dis 2012;15:e26-7.

92. Allanore $\mathrm{Y}$, Vignaux $\mathrm{O}$, Arnaud L, et al. Effects of corticosteroids and immunosuppressors on idiopathic inflammatory myopathy related myocarditis evaluated by magnetic resonance imaging. Ann Rheum Dis 2006;65:249-52.

93. Touma Z, Arayssi T, Kibbi L, et al. Successful treatment of cardiac involvement in dermatomyositis with rituximab. Joint Bone Spine 2008;75:334-7.

94. Danieli MG, Gelardi C, Guerra F, et al. Cardiac involvement in polymyositis and dermatomyositis. Autoimmun Rev 2016;15:462-5.

95. Erlacher P, Lercher A, Falkensammer J, et al. Cardiac troponin and beta-type myosin heavy chain concentrations in patients with polymyositis or dermatomyositis. Clin Chim Acta 2001;306:27-33.

96. Aggarwal R, Lebiedz-Odrobina D, Sinha A, et al. Serum cardiac troponin $\mathrm{T}$, but not troponin I, is elevated in idiopathic inflammatory myopathies. J Rheumatol 2009;36:2711-14.

97. Schwarzmeier JD, Hamwi A, Preisel M, et al. Positive troponin T without cardiac involvement in inclusion body myositis. Hum Pathol 2005;36:917-21.

98. Cox FM, Delgado V, Verschuuren JJ, et al. The heart in sporadic inclusion body myositis: a study in 51 patients. $J$ Neurol 2010;257:447-51. 